\title{
Pequeña filosofía de la aceleración de la historia *
}

\author{
OLIVIER REMAUD ${ }^{1}$
}

École des Hautes Études en Sciences Sociales, París

\begin{abstract}
RESUMEN. La aceleración de la historia es un asunto de creencias. Ella introduce en el mundo social cambios fundamentales y sugiere al mismo tiempo que los suscribimos. Pero si los individuos están prestos a admitir una nueva creencia en lo que respecta a la naturaleza cambiante del presente, han de adaptarla aún a sus creencias precedentes. Este conjunto de creencias disponible proporciona así respuestas variadas cuando las personas reaccionan a dilemas situacionales e intentan conciliar su interpretación de la realidad con el nuevo espíritu de la época.
\end{abstract}

Palabras clave: aceleración, creencia, época, cambio, situación histórica.
ABSTRACT. The acceleration of History is a matter of beliefs. It introduces into the social world fundamental changes and suggests at the same time that we acquiesce on them. But if people are prepared to admit a new belief about the changing nature of the epoch, they still have to accommodate it to their old beliefs. This present web of beliefs provides then a series of responses as people react to situational dilemmas, trying to conciliate their understanding of the reality with the new spirit of the age.

Key words: acceleration, belief, epoch, change, historical situation.

Durante los primeros meses de la Segunda Guerra Mundial, el ensayista alemán Sebastian Haffner anotó en el manuscrito de sus memorias que antes del fatídico año 1933, durante el cual Hindenburg nombró canciller a Hitler, todo el mundo era aún más o menos capaz de ser coherente consigo mismo. Algunos acontecimientos podían superar a los individuos y adquirir proporciones gigantescas, pero la esfera de la vida privada seguía relativamente indemne, al abrigo en cierto modo de la trampa institucionalizada ${ }^{2}$. Pero el presentimiento de la locura totalitaria indujo a quien poco después iba a iniciar, durante su exilio londinense, una carrera de periodista a pensar que un acontecimiento es decisivo stricto sensu cuando afecta al dominio íntimo hasta el

* Traducción castellana de Jorge Navarro Pérez.

${ }^{1}$ Filósofo, maître de conférences en la École des Hautes Études en Sciences Sociales, París. Última obra publicada: Les archives de l'humanité. Essai sur la philosophie de Vico, París, Seuil, 2004.

2 S. Haffner, Histoire d'un Allemand. Souvenirs 1914-1933, trad. fr. B. Hébert, París, Actes Sud, 2002, pp. 19-21. 
punto de sacarlo de quicio y formular casos de conciencia inextricables. La historiografía clásica no prestó atención durante mucho tiempo a las variaciones de intensidad individual suscitadas por esa especie de terremoto que hace presagiar de repente lo peor. Prefirió interesarse por las modificaciones de paso igual y regular que suelen darse en la mayoría de los regímenes políticos. Sin duda, el ascenso del nacionalsocialismo es una experiencia extrema de cambio de la velocidad histórica. Al contrario de las dinámicas en evolución constante, que privilegian el escenario psicológico de la adaptación tranquila a las continuidades largas, todas las aceleraciones de la historia tienen, cuando se producen, la consecuencia de electrizar en grados diversos el sistema nervioso de una sociedad y quebrantar el armazón de las identidades personales.

Más recientemente, las aventuras europeas de las «revoluciones de terciopelo» han mostrado que las rupturas de cadencia del proceso histórico son casi siempre inesperadas en el orden de la vida cotidiana. La evidencia de un cambio grande se impone a menudo con la fuerza de una sorpresa. La reconocemos mediante unos signos indudables, como la abolición inmediata de las viejas fronteras administrativas, un grado inusual de efervescencia social y una intensificación palpable de las expectativas colectivas. El marco tradicional de la experiencia se embarulla de repente, y los acontecimientos se enlazan unos con otros como los vagones de un tren cuya dirección ignoran los viajeros. La imagen canónica del tren del tiempo que va cada vez más rápido, mientras los paisajes se suceden al ritmo de una alternancia colorida, está en el centro de las filosofías del progreso, que organizan el cambio en relación con un terminus ad quem. Y cuando falta el conocimiento de la meta, esta imagen nos muestra el sentimiento general, sorprendentemente vago, que prevalece en esos instantes y que se escapa al lenguaje claro de la narración omnisciente, mientras que la amplia paleta de impresiones penetrantes que lo caracterizan expresa la unidad huidiza de la época en plena metamorfosis. Las aceleraciones de la historia reaniman la existencia en común. Alertan a las consciencias individuales de transición en los dos modos conjugados del sobresalto y el estremecimiento. Valoran sobre seguro la sensación del esfuerzo mediante el cual intentamos caminar al mismo ritmo que el proceso que se embala y retardan la inteligencia del camino que se habrá recorrido realmente. En otro contexto, John Dewey, confrontado con la impaciencia atmosférica de los años veinte del siglo XX, se interroga sobre las condiciones para ordenar bien un espacio público demasiado móvil que los avances tecnológicos recientes no dejan de reformular ${ }^{3}$. Esta observación inquieta, que se basa en las diferencias de ritmo que provocaron los progresos científicos, no

3 J. Dewey, The Public and Its Problems. An Essay in Political Inquiry, Chicago, Gateway Books, 1946, p. 140 ( How can a pubic be organized, we may ask, when literally it does not stay in place?»). 
vale sólo para la sociedad americana de entreguerras. Reivindica la necesidad de esforzarse en reunir los ingredientes del sentido común cuando las aceleraciones de la historia no indican por sí mismas una destinación precisa.

\section{La paradoja del acontecimiento desencadenante}

El acontecimiento que traduce una aceleración de la historia se distingue del que expresa un simple cambio de perspectiva individual. Veamos el ejemplo de un estudiante que acaba de completar su formación universitaria: la entrada en el mercado de trabajo y la búsqueda de un puesto que represente puntos de inflexión mayores (los turning points de la sociología anglosajona). Si tiene éxito, este estudiante encontrará la perspectiva de una trayectoria estable. Pero si fracasa, multiplicará los contratos temporales y hará la penosa experiencia de una anomalía causal, pues los períodos regulares durante los que él se ha formado parecen tener menos consecuencias que los períodos más movidos, que ofrecen las oportunidades. Por tanto, los puntos de inflexión verdaderamente determinantes tienen la particularidad de que siempre acaban rediseñando una trayectoria profesional. Contienen, como indica Andrew Abbott, un potencial narrativo que la iniciativa personal o las amistades comprensivas contribuyen a realizar, y no se reducen a circunstancias azarosas ${ }^{4}$. Esta variación de carrera se inscribe en un proceso que está marcado teleológicamente. El individuo posee una representación de la meta. Actúa con vistas a maximizar las oportunidades de alcanzarla.

Aparte del hecho de que superan el marco de las acciones de un solo individuo, las aceleraciones de la historia aparecen a menudo, a la inversa, como desprovistas de finalidad. Más bien, en el momento en que se producen parecen ligadas a un acontecimiento desencadenante excepcional que se afirma primero hablando su propia lengua. Se objetará enseguida que un proceso orientado teleológicamente se parece a una aceleración de la historia. Nadie negará que el progreso científico conoció una etapa decisiva cuando un hombre caminó sobre la Luna y que este acontecimiento coronó los esfuerzos constantes de una comunidad de científicos y expertos. Esto es una definición disponible de los cambios de velocidad histórica. Tal vez sea la definición en la que todo el mundo piensa espontáneamente. El análisis de los factores materiales de la aceleración del proceso histórico, y en especial del desarrollo exponencial de los modos de transporte y comunicación que reducen las distancias de una manera casi mágica, muestra hasta qué punto la metáfora de Karl Marx, que en 1850 compara las revoluciones con «locomotoras de la historia», resume las experiencias temporales de toda una generación en mo-

4 A. Abbott, «On the Concept of Turning Point», en Time Matters. On Theory and Method, Chicago y Londres, University of Chicago Press, 2001, pp. 240-260. 
vimiento. La consciencia de los avances técnicos que marcan la segunda mitad del siglo XIX es un dato central del Historismus, entendido como una doctrina general del progreso ${ }^{5}$. Pero las aceleraciones de la historia no tienen más que correlatos objetivos y una definición en cierto modo fisicista de sus acontecimientos desencadenantes que las interpretaría únicamente en términos de sucesión pura y acumulativa y se conformaría con identificar sus límites cronológicos exteriores, sin poder señalar el tipo de cambio que ellas introducen ni identificar la gama de reacciones mentales contradictorias que suscitan (los análisis de Reinhart Koselleck, por no citar más autores, parten de esta constatación).

Los acontecimientos asociados a fases de aceleración sin finalidad legible son de un género particular. Trastornan el equilibrio entre las variaciones internas mínimas y la fuerza de inercia, por lo general máxima, de una sociedad estable. Sumergen a los individuos en el espesor nuevo de una actualidad imprevista, los obligan a menudo a reaccionar antes de actuar, y diseñan en el hueco del espacio público una línea divisoria irreductible entre un antes y un después. A la manera de una cámara de resonancia, estos acontecimientos repercuten y convierten en otras tantas historias personales a lo que sale del orden de lo político y crean a continuación una memoria indeleble que orienta por mucho tiempo el futuro de la acción. Por consiguiente, desde el punto de vista de quienes las viven en directo las aceleraciones de un proceso histórico se diferencian de los simples cambios de perspectiva e incluso de los procesos orientados teleológicamente por al menos tres aspectos: no son la consecuencia de un solo turning point, no restituyen a posteriori una trayectoria que habría sido premeditada, y el murmullo colectivo que ellas ocasionan parece al principio indescifrable. Dicho de otra manera, las aceleraciones son casi siempre la consecuencia del cruce de varios puntos de inflexión cuyo desenlace nadie consigue anticipar. La razón es sencilla: en el hueco de estas aceleraciones de la historia se aloja la paradoja del acontecimiento desencadenante.

Si analizamos ahora el ejemplo de una derrota militar, comprendemos que ésta nunca se explica in fine por el número de soldados presentes, por el sistema de reclutamiento que selecciona a mercenarios en detrimento de los profesionales, por la tasa elevada de pluviometría que vuelve pesado el terreno y reduce la visibilidad, por la evidente fatiga del estado mayor, ni siquiera por el grado de perfeccionamiento de las armas utilizadas. No es sólo la combinación de estas condiciones estructurales lo que provoca la derrota, sino también la diferencia específica que ellas introducen en el juego de las contingencias sincrónicas de la historia presentándose en un momento dado como acontecimiento individualizado. El historiador del ejército atribuye sin

5 Véase R. Koselleck, «Gibt es eine Beschleunigung der Geschichte?», en Zeitschichten. Studien zur Historik, Fráncfort, Suhrkamp, 2000, pp. 150-176. 
dilación al acontecimiento de una derrota militar el aspecto de un fenómeno unificado que una datación precisa contribuye a circunscribir. Le presta retrospectivamente una causalidad legible y englobante, pero se da cuenta de que también este acontecimiento es el fruto de una síntesis inestable de factores no determinantes por sí mismos, a la cual se añade el carácter singular e irrepetible de su formulación definitiva. El sentido del acontecimiento que imaginamos desencadenante desborda siempre la simple declaración de sus datos iniciales perceptibles.

Pero el curso regular del mundo no es trastornado por una derrota militar, y una aceleración de la historia no se produce verdaderamente si el acontecimiento de la debacle no entra a su vez en relación con otros acontecimientos o procesos desencadenantes. El estallido de un conflicto también depende, como se sabe, de unas reacciones gubernamentales imprevisibles y de eventuales lógicas secesionistas internas en las naciones implicadas, como atestigua cíclicamente el peso de los conflictos de intereses entre facciones rivales. Ningún acontecimiento desencadenante es químicamente puro. Lo que modifica los parámetros de la fuerza de inercia de una sociedad hasta el punto de reactivar el proceso global de sus operaciones colectivas es más bien la interacción entre acontecimientos considerados decisivos. Así pues, importa poco intentar medir la velocidad de un cambio social o histórico en particular, pues éste procede cada vez de una especie de frotamiento entre los diferentes ritmos de las circunstancias que lo componen en última instancia.

Abordada de esta manera, la paradoja del acontecimiento desencadenante se debe a que al fin y al cabo mezcla dos niveles de efectividad. Por una parte, el nivel público y visible, que es parcialmente descriptible, ya que no totalmente inteligible, y que los testigos directos colocan espontáneamente bajo la figura de la unidad (esto es la asignación de una causalidad monolítica). Por otra parte, el nivel combinatorio, invisible y opaco, en el que el hecho de la interacción se afirma y se construye en paralelo a los proyectos declarados o solamente deseados de los individuos (esto es la naturaleza profundamente solidaria o incluso interexpresiva de acontecimientos cuya talla resulta ser histórica). Esta paradoja explica que las aceleraciones de la historia sean unos procesos fuertemente indeterminados cuya intensificación, que se interpreta instintivamente en términos de una lógica de superación causal y acumulativa, remite de hecho a un orden combinatorio. Aunque las aceleraciones de la historia están emparentadas, en virtud de su complejidad interna, con el movimiento indefinido de las nubes, todo el mundo se empeña en traducirlas a los términos de la trayectoria rectilínea de una bola de billar a la que un empujón inicial basta para darle impulso (por retomar las dos representaciones del tiempo que Robert Musil opone constantemente). Ya se sabe que cuanto más serias son las consecuencias de un acontecimiento, menos fácil es pensarlo según sus causas. Sin embargo, siempre se le presta el rostro de un origen radical que provoca el paso brusco de una época a otra. 


\section{La mitología de la época}

Como ya he sugerido, ningún punto de vista absoluto es capaz de capturar el acontecimiento que se supone que desencadena una aceleración de la historia. Nunca se puede agotar, ni siquiera en el seno de una consciencia vigilante, todo lo que sucede en el presente inmediato. La naturaleza de un acontecimiento no sale a la luz durante el tiempo de su formulación. Si un acontecimiento se destaca de un fondo de uniformidad, introduce una diferencia que era imposible conocer a priori. Por tanto, no lo comprendemos más que con la condición expresa de insertarlo retrospectivamente en una serie temporal. En el plano de la epistemología histórica, el concepto de época permite distinguir el acontecimiento histórico, al que se atribuye clásicamente la cualidad de ser digno de una narración, de un acontecimiento que se esparce por el curso del tiempo y que no es útil recordar, pues no sirve a los fines de un relato memorable (éste es el argumento de Tucídides). La noción de época da forma al acontecimiento, lo clasifica integrándolo en el movimiento de «retrodicción sintética» (P. Veyne) que concluye lógicamente el mecanismo de reconocimiento histórico. Para nosotros, un acontecimiento no existe más que por sus consecuencias. La reflexión no puede tematizarlo más que a partir de los efectos que él produce, determinándolo a posteriori. Desde este punto de vista, la noción de época es un artefacto de la consciencia histórica. Se supone que proporciona un rudimento de explicación en la intersección de concomitancias cuyo resultado es el acontecimiento desencadenante. Johann Gustav Droysen recuerda a este respecto que las épocas tienen tan poca realidad en la historia como el trazado de los meridianos y los paralelos en la superficie de la Tierra ${ }^{6}$. Son ante todo fábulas útiles.

Lo sorprendente es que las aceleraciones de la historia extienden al registro de la vida ordinaria el uso de las ficciones categoriales. Mientras unos y otros intentan dar cuenta de los valores heterogéneos que surgen en un tiempo histórico que se acelera, constatan que el presente que tienen ante sus ojos escapa literalmente a toda tentativa de unificación, aunque sea provisional. La imposibilidad de ordenar las nuevas contingencias sincrónicas provoca entonces, de manera casi automática, conductas mentales de compensación. Las aceleraciones de la historia desorientan a los individuos, cada uno de los cuales se aferra a una mitología de la época para cualificar a un cambio repentino de cadencia que sólo se presenta desde el ángulo de una serie caótica de acontecimientos opacos. Al hacer esto, se aplica el utillaje de la época al presente y se intenta conferir un valor sintético a un tiempo que se está desplazando. Pero ya no se trata de restituir la vista de un templo a partir de las pocas columnas que quedan en pie y de recrear con un rodeo un sistema de ideas o

6 J. G. Droysen, Historik. Vorlesungen über Enzyklopädie und Methodologie der Geschichte (1857), ed. Peter Leyh, Stuttgart, Frommann-Holzboog, 1977, pp. 371-372. 
sentimientos caducos. Así pues, ¿qué significa esta reorientación mecánica, en cierto modo refleja, del sentido histórico hacia la materia fluida y borbollante, privada de finalidad, de un presente en plena mutación?

Para caracterizar a una época del pasado, el historiador utiliza fechas clave. La datación es el instrumento necesario de la comprensión histórica que intenta aislar períodos bien definidos para mostrar a continuación las regularidades históricas transitorias. Pero el hecho de datar no permite por sí mismo nombrar la variación y cualificar a sus modalidades propias. Hay que encontrar las semejanzas de familia que unen acontecimientos aparentemente heterogéneos. En este sentido, la periodización implica una práctica de reagrupaciones por semejanzas. Se convierte en una fuente de errores cuando erige en carácter esencial de un siglo unos rasgos culturales dominantes y explica, por ejemplo, la Italia del siglo XVII mediante la edad barroca. Un reflejo de subsunción idéntica guía al individuo que se empeña en atribuir el carácter de una época a un tiempo que se acelera. Confiriendo al presente incoativo la forma de una duración pasada e históricamente reconstituida, el individuo moviliza subrepticiamente el significado holista del razonamiento periodizador del historiador para descifrar lo que no comprende inmediatamente. Frena simbólicamente el movimiento del tiempo que avanza, suspende la agitación de su espíritu y confunde la parte y el todo, pues deduce desde un acontecimiento que se impone el sentido global del proceso que se inaugura. Pero al mismo tiempo minimiza la indeterminación enigmática de este proceso sometiéndolo a la ilusión de un acontecimiento único para a continuación enganchar mejor todos los demás acontecimientos a esta medida inicial. El individuo cierra un tiempo que estaba abierto y se empeña en resolver la paradoja del acontecimiento desencadenante.

La identificación del presente como época proporciona el sentimiento de estar reduciendo la liosa polisemia de las fases de aceleración de la historia. Atribuir el aspecto de unidad temporal al presente equivale a distanciar el acontecimiento que perturba para no perderse en el surgimiento de la novedad y organizar una primera racionalización de la percepción del cambio. $\mathrm{La}$ necesidad apremiante de nombrar la actualidad con los términos de una época nueva, sin esperar a conocer mejor el detalle de lo que cambia, se formula significativamente cuando la experiencia social de los individuos está atravesada por series de incertezas que trastornan sus comportamientos habituales y que desplazan las referencias temporales adquiridas. Atribuyendo el nombre de época, se cree disponer de una representación estable de un tiempo perpetuum mobile que no sólo llena la distancia entre las rejillas explicativas disponibles y la realidad cambiante del mundo, sino que además disminuye la tensión que resulta de la brecha abierta entre el pasado y el presente. En este uso compensador se mezclan la envidia de la síntesis y la intuición de cierta impotencia. Así comprendida, la categoría de época es un principio regulador de la consciencia histórica desorientada. 


\section{Este extraño presente}

La noción de época posee, verosímilmente, un fuerte valor de compensación existencial. Intenta conjurar la inquietud que resulta de la indecisión histórica. Instrumento privilegiado de la consciencia de transición y de todas las declaraciones de eras nuevas, la noción de época registra los signos de los tiempos que cambian bruscamente. Aplicada a un proceso que se acelera, implica una gran cantidad de actitudes ex hypothesi. La noción de época traduce la ansiedad, el presentimiento o los deseos de orientación que los acontecimientos imprevistos suscitan y desempeña en cierto modo la función de una metáfora, en el sentido original de Hans Blumenberg ${ }^{7}$. La consciencia de transición se adapta así a las variaciones repentinas del tiempo colectivo y a los episodios particulares que las señalan. Pero ¿cómo interpretar entonces la convicción, expresada a menudo, de que cambiamos de época (y no simplemente que un acontecimiento excepcional se acaba de producir)?

El sentimiento de una aceleración de la historia es indisociable de la imputación artificial de un espíritu del tiempo que se supone que resume la sustancia del cambio constatado. Isaiah Berlin observa a este respecto que los miembros de la acusación tienen una ventaja fácil en el proceso eterno que opone a quienes no aprecian su época a quienes la adulan. Afirmando que los retrógrados y los reaccionarios se refugian en la idealización romántica del pasado, a partir del hecho de su ignorancia de las nuevas leyes de la historia y de la lógica necesaria de sus acontecimientos, los acusan de anacronismo en la medida exacta en que no expresan el «modelo más general de su propia época» ${ }^{8}$. La mitología de la época, mediante la cual cada uno intenta disolver la paradoja del acontecimiento desencadenante, presupone idénticamente un Zeitgeist, un espíritu general del tiempo que determina implícitamente una relación de congruencia entre la forma del tiempo en movimiento y el contenido de las creencias colectivas que lo acompañan.

En efecto, las aceleraciones de la historia producen una forma de sincronía universal. Imponen a todo el mundo un ritmo inédito y nos obligan a todos a comportarnos de acuerdo con esta nueva velocidad. Plebiscitan la tendencia alegórica que se aloja en el corazón de la vida en común y que consiste sobre todo en relacionar los actos de los unos y los otros con la unidad ficticia de una época. Las conductas ordinarias reflejan el nuevo rostro del tiempo. Caminamos, comemos y amamos al ritmo de la época. Es imposible sustraerse a la atracción de su modelo. Esta sincronía, que exacerba la tentación del mimetismo universal y de la que la moda sólo es uno de sus aspectos, oculta el hecho íntimo de una pluralidad de vidas disímiles. Las aceleraciones de la

7 Véase H. Blumenberg, Paradigmen zu einer Metaphorologie (1960), Fráncfort, Suhrkamp, 1998.

${ }^{8}$ I. Berlin, Le sens des realités, trad. fr. G. Delannoi y A. Butin, París, Syrtes, 2003, p. 31. 
historia no dejan de fragmentar las existencias personales. Ante el andamiaje íntimo de sus mundos diferentes, la memoria pierde el sentido de la linealidad. El tiempo de la infancia, como sugiere Stefan Zweig en Die Welt von gestern (1934), ya no es simplemente una de las edades de una sola vida que se aleja naturalmente, sino que adquiere el sentido de un episodio que reverbera el rostro ya marchito de una época pasada. La intensidad del momento de aceleración histórica es tan fuerte que revela, en el sentido fotográfico del término, todos los demás períodos de la vida. A menudo, el individuo que vive en el corazón de un acontecimiento desencadenante está obligado a reconstruir los puentes rotos entre lo antiguo y lo nuevo para intentar reconstituir su sentido interno de la continuidad. Cuando le resulta imposible reapropiarse su presente, se vuelve efectivamente anacrónico.

Cada aceleración de la historia desarraiga a los individuos. Y la convicción de que cambiamos de época expresa una experiencia de desarraigo. Pero esta experiencia se conjuga de varias maneras. Durante las fases de aceleración de la historia, unos eligen adherirse a los contornos borrosos de un tiempo en formación, mientras que otros prefieren apartar la mirada de esa silueta decididamente indecisa. Ya nos sintamos anacrónicos o no, atrasados respecto de la actualidad o al gusto del día, lo esencial es comprender que las aceleraciones de la historia exigen siempre traducir los acontecimientos de una época cuya lengua nadie conoce verdaderamente. Hasta el punto de que ellas dictan una alternativa. $\mathrm{O}$ bien se considera que la nueva época dice más o menos lo mismo que la anterior, que sus creencias son razonables y que su forma general es a fin de cuentas sensiblemente idéntica. Esta variación del «principle of charity» de los filósofos americanos Willard Van Orman Quine y Donald Davidson diseña un consenso posible entre los estilos de cada época. Presupone una racionalidad histórica común (lo que sucede es del mismo tipo que lo que ya sucedió). El progresista y el conservador se unen en el postulado de una familiaridad mínima entre las épocas. Se diferencian en que uno atribuye al cambio el poder de redefinir el estado presente de la sociedad, mientras que el otro lo considera secundario y siempre lo mide por el rasero de un orden institucional ya existente. O bien se declara que los nuevos tiempos contienen un índice de extrañeza tan alto que parecen ininteligibles e incompatibles con las formas actuales de vida común (lo que sucede no tiene ningún lazo familiar con lo que ya sucedió). En este caso hay un riesgo grande de naturalizar la aceleración sufrida y de asociarla a un proceso inevitable que expresa la fuerza de las cosas. Con conocimiento de causa, el retrógrado o el reaccionario (por retomar las categorías analizadas por Isaiah Berlin) pueden adelantarse a sus acusadores y elegir interpretar las aceleraciones de la historia en los términos de una marcha inexorable para finalmente rechazarlas arguyendo que los factores superiores de desarrollo disuelven la libertad de los individuos. Ya no intentan traducir lo nuevo a lo antiguo, sino incrementar el carácter extraño o incluso teratológico del cambio. 
El sentimiento de pérdida de la experiencia del presente, sumergida indebidamente por una imagen de época juzgada incongruente, es a veces comparable con una impresión de duelo anticipado. A menudo, quien rechaza la imagen colectiva de la época que se está formando ha nacido en la época cuyas coordenadas se modifican. Habiendo perdido la conexión con su contexto original, ya no consigue enlazar la posibilidad de una experiencia completa con un presente que se mueve sin cesar. Tampoco acepta representárselo como aquello de lo que a continuación tal vez hará una experiencia sintética. Aunque presupone que una forma de vida común exige una especie de conciudadanía de época única, él no comprende que las aceleraciones de la historia, que redefinen los límites del espacio público y perturban todos los reflejos de pertenencia, disocian naturalmente estos dos criterios. Una vez adquirida la convicción profunda de que las aceleraciones de la historia dan lugar a un espíritu del tiempo rival que contradice radicalmente a sus aspiraciones personales, elige finalmente sustraerse a la tendencia general de su época, tal como él la percibe, remontándose desde la simple constatación de que no comparte las mismas creencias a la certeza firme de que ya no hay creencias verdaderamente comunes. De esta manera, él vuelve incompatibles tres elementos del espacio público que siempre han sido complementarios: el núcleo admitido implícitamente de las obligaciones recíprocas que una sociedad no puede demostrar cada segundo sin paralizar la acción, el intercambio necesario de opiniones contradictorias y la diversidad preservada de los sentimientos de épocas (las experiencias íntimas de no contemporaneidad). La cualificación de una tendencia homogénea de la época presente nunca es inocente. Forma parte, cobrando, de la edificación del juicio político. Es aquí donde la aceleración de la historia hace competir a las imágenes de épocas.

Se ha podido anotar que el Renacimiento que Jacob Burckhardt describe en Die Kultur der Renaissance in Italien (1860) representa todo lo que no es la sociedad industrial que se acelera durante la segunda mitad del siglo XIX (H. White). El nacionalismo guerrero, la amenaza de las grandes potencias para los países pequeños, el inflamiento de un Estado central que domina la cultura, la fe ciega en el progreso técnico, la mediocridad como propiedad inherente a la democracia: todos estos elementos marcan la evolución reciente de la modernidad. Por el contrario, el Renacimiento es la época de los grandes hombres que realizan el proceso de civilización y que equilibran las coacciones civiles con el dominio de los sentimientos; además, desconocen la soledad del individuo en las sociedades de masas y la inflación de los intereses materiales. Pero es más verosímil que el contraste se deba a que a Burckhardt le resulta difícil figurarse el presente como una época cultural que concentra de manera ideal una pluralidad de tendencias políticas, morales o estéticas convergentes. Burckhardt consigue desarrollar su imaginación para definir los contornos espirituales de una época como la del Renacimiento italiano, pero constata la imposibilidad de presentar una Anschauung, una imagen vi- 
sual del presente. Historiador de profesión, Burckhardt sabe muy bien que es ilusorio intentar producir una síntesis del presente que se acelera y que el método óptico totalizador que él preconiza en el plano de la escritura de la historia no sirve más que para ciertas épocas del pasado. Burckhardt racionaliza la mitología espontánea de la época que he evocado y que muestra operaciones ordinarias del sentido común desorientado. Pero al mismo tiempo Burckhardt recrea otra mitología, la que transforma la época del Renacimiento en un tipo esencial, en un fragmento soñado de la historia universal (a veces es la Edad Media quien se encarga de esta función) ${ }^{9}$. Haciendo esto, Burckhardt aumenta la distancia entre el período del Renacimiento que se objetiva en los términos de una especie de acontecimiento total, verdadero emblema de la civilización, y la Europa de su tiempo, aquejada de una enfermedad sombría que anuncia una barbarie probablemente inevitable.

Sin embargo, todo depende del sentido que se dé a la oposición entre el mundo de ayer y el mundo de hoy. En su reseña del libro de Ferdinand Tönnies Gemeinschaft und Gesellschaft (1887), Émile Durkheim observa por ejemplo que el problema no está en el análisis de la «comunidad», entendida como un modelo orgánico de los grupos rurales en los que los hombres están unidos pese a todas las distinciones. En cambio, el problema aparece nítidamente cuando se trata de caracterizar a la «sociedad» como una composición mecánica de la hostilidad generalizada, a imagen de lo que sucede en las grandes ciudades, donde los hombres son diferentes unos de otros pese a sus vínculos. ¿Por qué razones, pregunta el sociólogo francés, se supone que los contextos humanos que conocen aceleraciones permanentes son menos orgánicos y menos internos que los que ignoran casi todo cambio? ${ }^{10}$. La razón es que se vuelve posible hacer que se sucedan las épocas (en este caso las del comunismo y el socialismo) para someter a continuación la evolución histórica y política en conjunto a la apreciación de un juicio de decadencia. Leyendo a Tönnies, Durkheim sospecha que la aceleración de la historia que caracteriza al tiempo presente se convierte de esta manera en el término pervertido de un desarrollo único y que el ideal de la proximidad rural está magnificado.

Estos dos ejemplos muestran que la lógica de la competencia entre las imágenes de épocas es el resultado directo de una experiencia de aceleración de la historia. Pero presentan un juego de reacciones diferentes a un mismo fenómeno, el de la industrialización. En el caso de Burckhardt, una imagen de la época ideal proporciona el marco invertido de un presente desencantado y no totalizable. En el caso de Tönnies, el mundo contemporáneo simboliza una fase inevitable de desviación de una evolución histórica cuyo futuro es oscuro. Los diagnósticos de la Kulturkritik refuerzan el contraste entre el pasado y

9 J. Burckhardt, Weltgeschichtliche Betrachtungen (1905), ed. R. Marx, Stuttgart, Kröner, 1978, p. 66.

10 É. Durkheim, «Communauté et société selon Tönnies» (1889), en Textes 1. Éléments d'une théorie sociale, París, Minuit, 1975, pp. 383-390. 
el presente, entre edades auténticas y tiempos que alteran el sentido histórico. Sin embargo, cada cual hace a su manera chapuzas mitográficas con las categorías generales de proceso, acontecimiento o época. Esta alquimia categorial da su color particular a cada visión pesimista del mundo. Este punto no se le escapó a Robert Musil, que unas décadas después observa que a menudo el individuo fabrica durante esos momentos en que se experimenta una aceleración sin finalidad unos útiles de este tipo para apreciar la decadencia. Tanto para el sabio recluido en su torre de marfil como para el hombre ordinario que da vueltas por las grandes ciudades, la categoría de época desempeña finalmente la misma función que la noción mágica y misteriosa de alma. Todo el mundo puede invocarla para estigmatizar la incertidumbre que caracteriza a las sociedades contemporáneas materialistas o proclamar la degeneración fatal del proceso histórico. En un «pesimismo bien entendido», la época presente es acusada de todos los males imaginables ${ }^{11}$. Cuando reina la confusión, la categoría de época posee un estatuto que es más o menos el mismo que el de los dioses de Homero.

\section{El horizonte del juicio politico}

En el relato de Edgar Poe que proporciona a Norbert Elias un título y un argumento de obertura para la segunda sección de su libro Engagement und Distanzierung, un maelström gigantesco engulle el barco de dos hermanos que están pescando. Uno de ellos sobrevive gracias a una simple deducción instantánea. Tras haber observado que las regularidades giratorias producidas por el torbellino aspiran más rápidamente los objetos grandes que los pequeños objetos cilíndricos, llega a la conclusión de que le conviene encadenarse a un barril y saltar por la borda. Mientras que su hermano, paralizado por el miedo, se ahoga, él reaparece en la superficie gracias a una boya y a que el movimiento de las aguas se ha calmado. Norbert Elias saca partido de esta parábola para su concepción del «doble vínculo» entre el individuo y el acontecimiento. Llega a la conclusión de que un umbral de autocontrol ha permitido al superviviente reducir su miedo, aprovechar un momento de concentración para cambiarlo en teoría y esperar así a que acabe el maelström ${ }^{12}$.

Sucede a menudo que las condiciones concretas de una experiencia histórica nueva hunden a los individuos en una situación que se parece a un torbellino, sin que sepan que sus vidas dependen de él, como en la parábola de los dos hermanos pescadores. Las aceleraciones de la historia inscriben a los individuos en un proceso que desconocen y que se sustrae por principio a su

11 R. Musil, L’homme sans qualités, trad. fr. P. Jaccottet, París, Points-Seuil, 1982, p. 73.

12 N. Elias, Engagement et distanciation. Contributions à la sociologie de la connaissance (1983), trad. fr. M. Hulin, París, Fayard, 1993, pp. 75-81. 
control. Pero a veces los acontecimientos autorizan a unos o a otros a reajustar su pensamiento a la situación presente para identificar en la efervescencia de la historia algunas de las razones que han modificado de repente el entorno en que viven y adquirir elementos de comprensión de un proceso que antes parecía ininteligible. Unos breves instantes de representación se construyen en el momento del acontecimiento y permiten elaborar una imagen parcial de él. La consciencia de transición responde a la angustia de lo desconocido provocada por las aceleraciones de la historia elaborando así una conducta de auto-distanciamiento, instituyendo una distancia de dominio emocional. Ésta se forma en el cruce de dos relaciones, la afectiva que va de uno a uno y la objetiva que va de uno al proceso general. Evidentemente, en este tipo de experiencia histórica la consciencia no es un principio motor. Ella ni es constituyente ni está verdaderamente constituida. La lógica de reflexividad histórica depende más bien de una disposición afectiva que fabrica rápidamente el marco formal de interpretación.

¿En qué condiciones se puede traducir este afinamiento del sentimiento de época a los términos de un juicio político aplicable a la nueva situación? Regresemos brevemente a John Dewey a modo de conclusión abierta. Examinando el estado de la democracia americana, Dewey constata la confusión extrema de su tiempo. La inseguridad y el desempleo son los rasgos dominantes de la sociedad actual, mientras que todo el mundo se ahoga en la nueva civilización del dinero inmediato, perdiendo la seguridad de una finalidad objetiva a largo plazo de sus acciones. Todos estos elementos son el resultado de un desarrollo tecnológico desigual. Contribuyen a alejar a la "Gran Sociedad» (Great Society), que es creada por la electricidad, del proyecto de «Gran Comunidad» (Great Community) que el uso de la razón democrática requiere. Al utilizar estas dos expresiones, Dewey tal vez esté pensando en la distinción de Tönnies. Significativamente, Dewey no las desarrolla en el sentido de una crítica compensadora o incluso nostálgica de la aceleración de la historia. En su opinión, el problema de las sociedades tecnológicas y de la civilización material en general no es que ellas agotan los recursos de la cultura y disuelven la inventiva personal en la masa informe, sino que todo el mundo se pone a multiplicar el número de espacios públicos pequeños, los cuales se derivan de iniciativas personales, sin proporcionar los medios para realimentar constantemente el espacio público común. La democracia periclita cuando el individuo ya no puede dominar en este universo de valores fragmentado las consecuencias indirectas de sus propias acciones. En cambio, la democracia revive si el individuo consigue eso y si se esfuerza en enganchar la diversidad de esos mundos de valores a la imaginación siempre válida de un universo de creencias compartidas, para reorientar el conjunto de nuevos intereses locales hacia un sentido público universal ${ }^{13}$.

13 J. Dewey, The Public and Its Problems, pp. 131-137. 
Este razonamiento es instructivo por varios motivos. John Dewey adivina que los escenarios de la acción individual se complican cada vez más en las sociedades en las que se dan aceleraciones tecnológicas. En el seno de un mundo que incrementa la fuerza de las máquinas y que aumenta considerablemente el peso de los intereses industriales, Dewey comprende que cada cual es susceptible de ser confrontado con las consecuencias de un complejo de acciones carentes en cierto modo de sujetos y en el que él no ha participado. Por eso, Dewey considera indispensable interpretar las variaciones del comportamiento electoral de los ciudadanos desamparados por las aceleraciones de la historia, evaluar en su justa medida el peso de los elementos impersonales, percibir la eventual consonancia disimulada de ciertos acontecimientos, en pocas palabras: distinguir lo esencial de lo inesencial y lo particular de lo general para prevenir el riesgo de la apatía política. De ahí que Dewey proponga perseguir varios objetivos al mismo tiempo, por ejemplo: fijar las formas asociativas, organizar la pluralidad de los sentidos comunes o incluso determinar los límites positivos de la participación intencional. En lugar de oponer el mundo antiguo del cara a cara y de la totalidad cerrada al universo dividido de la modernidad, Dewey anula las dos tentaciones propiciatorias de abandonar la política y demonizar el presente, prefiriendo a ellas unas dosis sutiles de sabiduría práctica. En los momentos en que la historia se acelera, la lucidez política recomienda probablemente adoptar una actitud crítica de dimensiones variables, delimitar las capacidades positivas de la época desmarcándose de la mentalidad de epígonos y, por consiguiente, vivir con su tiempo sin ser su creatura, según la máxima de Johann Friedrich von Schiller ${ }^{14}$.

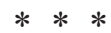

He sugerido aquí que la temática de la aceleración de la historia puede abordarse al menos de dos maneras. Una de ellas determina la historia según el eje acumulativo de los progresos técnicos y solicita una representación historicista de la noción de época, pues relaciona todo cambio de velocidad con la nueva etapa de un orden de desarrollo más amplio. La otra manera define la historia como un proceso sin finalidad legible cuya intensificación se explica por un juego complejo de factores interactivos y que utiliza la categoría de época como un objeto de creencia compensadora. Lo importante es entrever, al término de estas reflexiones transversales, que estas dos caracterizaciones son indisociables y que conviene aprehender las variaciones repentinas de los ritmos colectivos integrando el argumento del progreso tecnológico en una filosofía más amplia de las creencias sociales. Las aceleraciones de la historia

14 J. F. von Schiller, Über die ästhetische Erziehung des Menschen (1795), en Werke und Briefe. Theoretische Schriften, vol. 8, ed. R.-P. Janz, Fráncfort, Deutscher Klassiker Verlag, 1992, p. 586 ("Lebe mit deinem Jahrhundert, aber sei nicht sein Geschöpf»). 
suelen suscitar en la consciencia de transición unos procedimientos dilatorios que intentan incrementar la alteridad política que surge de un presente en ebullición. Nuestras sensibilidades actuales se vuelven de este modo cada vez más normativas. Identificando las razones por las que se inventan así figuras contrastantes del presente a partir de su tendencia general supuesta, tal vez se esclarecerían ciertos aspectos de la vieja oposición entre la cultura y la civilización, que hoy resurge de sus cenizas. 